\title{
TECHNIQUES OF VISUAL COMMUNICATION IN ARCHITECTURAL DESIGN
}

\author{
MACIEJ WOJCIECH KOWALCZYK \\ Faculty of Architecture, Warsaw University of Technology, \\ ul. Koszykowa 55, 00-659 Warsaw, Poland \\ Email address: mckowalczyk@gmail.com \\ ORCID: https://orcid.org/0000-0002-8396-9655

\section{AGNIESZKA LEWANDOWSKA} \\ Faculty of Architecture, Warsaw University of Technology, \\ ul. Koszykowa 55, 00-659 Warsaw, Poland \\ Email address: ga.lewandowska@gmail.com \\ ORCID: https://orcid.org/0000-0001-6542-5948
}

\begin{abstract}
Aim. The article discusses the methods and techniques serving the architectural presentation to a diverse audience. The methods of architectural presentation as a key element in the dialogue with the future user of the designed space or building allow presenting the newly designed space to the recipient.

Methods. The described ways of presenting the project were divided into material and virtual. The article discusses the most commonly used methods of architectural presentation such as diagrams, visualisation, physical model, virtual model, video, and collage. It analyses their usefulness in terms of reliable communication aiming to inform future users about planned changes. The authors describe in detail the use of architectural models as a technique used to present the project to both professional and non-professional recipients. The pros and cons of each method are discussed.

Results and Conclusion. The right choice of presentation method for the addressee allows for a better understanding of the presented idea and, as a result, for more informed choices made by the society, e.g. during public consultations, or by professional decision-making bodies in matters of public space and new architectural objects. There is a wide array of methods for imaging the project vision available today that have their individual features, which can favour or negatively affect the reception of works by falsifying reality or its partial message.

Key words: architecture, visual communication, architectural presentation, visualisations, architectural model, decision-making
\end{abstract}




\section{INTRODUCTION}

A rchitectural and urban designs, which are products of engineering thought, use a developed technical language that reflects the designed space. It consists traditionally of two and three-dimensional drawings, symbols and diagrams similar to other technical designs. What distinguishes architecture from some design fields is the parallel desire or need to convey a design idea in the form of three-dimensional space, so that it is understandable to every recipient, including its future users or those who decide about its creation. The intention is to allow the addressee to imagine a given space, understand functional, spatial and formal relationships, through creating a clear and coherent image. In addition, some of the techniques are aimed at building the right atmosphere, referring to the experiences and emotions of the recipient, thus affecting its reception. It is an element that combines architecture with techniques used in marketing, where the feature of the promoted product becomes more important than a product itself, and thus goes to the right recipients, encouraging them to buy. Similarly in architecture, a properly created image showing the atmosphere of space can become more important than space itself, not focusing on its physical features, but referring to the experiences of the recipient. This phenomenon does not necessarily have to be negative unless it serves to mystify or deliberately hide the negative features of a given space. Emphasizes the accuracy of mapping space or its intangible aspects and presenting the genius loci of the designed space, the choice of visual communication technique in architecture is, therefore, the basic decision in its selection. The atmosphere created by the author influences the reception of the project as such. Therefore the selection of the appropriate communication technique becomes extremely important considering the impression it is supposed to make on the recipient.

A separate aspect is the recipients themselves. They can be divided into professionals, i.e. architects, urban planners, people dealing with space, and non-professionals, such as political decision-makers, residents, investors, etc. All these groups are particularly interested in the nature of the planned space, but they differ in the perception skills of a given presentation technique, which results from their education and individual predispositions. Here again, the common denominator is experience, resulting from interacting with a diverse space, to which a representative of each of these groups can refer. Today most people live in cities and are users of flats, offices, squares, streets, stations, cafes, etc.. Referring to these common experiences based on associations, creating a familiar atmosphere is the essence of architectural communication.

In the article, the authors focus on architectural presentation which aims to present a reliable and the most objective picture of the future space to the interested representatives of society, decision-makers on projects. The main research question is, therefore, the issue of choosing a presentation tool so that the recipient understands the complex design issue as much as possible and has the opportunity to consciously receive it. This is an important issue in the case 
of public consultations, information on public projects by public institutions, but also in the case of presenting projects to public or individual investors. Properly selected methods of presentation affect the reliable or false image of a design idea, thereby fostering its acceptance or the possibility of rejection. Hence, the perception of the project by future users or decision-makers has an impact on the space in which we live or work.

\section{TECHNIQUES AND METHODS OF ARCHITECTURAL PRESENTATION}

The authors of the article divided modern methods of architectural presentation into material and virtual. Material methods comprise physical models, all forms of architectural graphics, e.g. two- and three-dimensional drawings, collages, visualisations, created using manual or computer tools. These forms of communication also include traditional architectural presentation methods i.e. plans, cross-sections, details.

Virtual methods, in turn, are those created using advanced computer techniques, i.e. virtual models, enabling the generation of any views, animations, virtual walks. One should also mention virtual reality (VR), defined by Sherman and Judkins in 1992, whose aim is to reproduce the real project on many levels. However, advanced technologies are needed for all these presentation techniques.

Below, the authors discuss the most commonly used methods of presenting an architectural design, encountered when presenting an idea to both a professional and non-professional recipient. These are two-dimensional visualisations and three-dimensional architectural models.

\section{VISUALISATION}

Architectural visualisations (renderings) are currently the most common design presentation technique. Created images most often use as a base 3D models built in advance. There are also visualisations in the form of images or collages, created using computer programs, manually and with combined techniques. Visualisations are used for the presentation of the project by architects, interior designers or developers. In this case, the creation serves to present a three-dimensional project in the form of a two-dimensional image.

At the design stage, visualisations are used as a tool to test various architectural solutions. On the basis of the computer model itself and the image generated from the said model, one can analyse among others building forms, light or setting in context. Working visualisations (preview) are therefore used to test different finishing materials or to examine the features of the building and the designed space at different times of the day and year. They are irreplaceable for detailed analysis of the impact of light on the design, the element that brings out its architectural form. 
At the final design stage, visualisations are used as tools for project promotion. With their help, the architect presents the building (space, interior) - he or she 'sells' the idea of the project. Visualisations are an imperfect presentation tool due to their two-dimensionality; the designer cannot present all the complex elements of the design. The style of visual narrative used, e.g. too technical or too abstract, may also disturb the perception of a project itself. With the help of virtual modelling software, it is possible to manipulate both the design itself and its surroundings: change the viewing angle, idealise the existing space, subtract or add elements, artificially light, affecting the reception of the design.

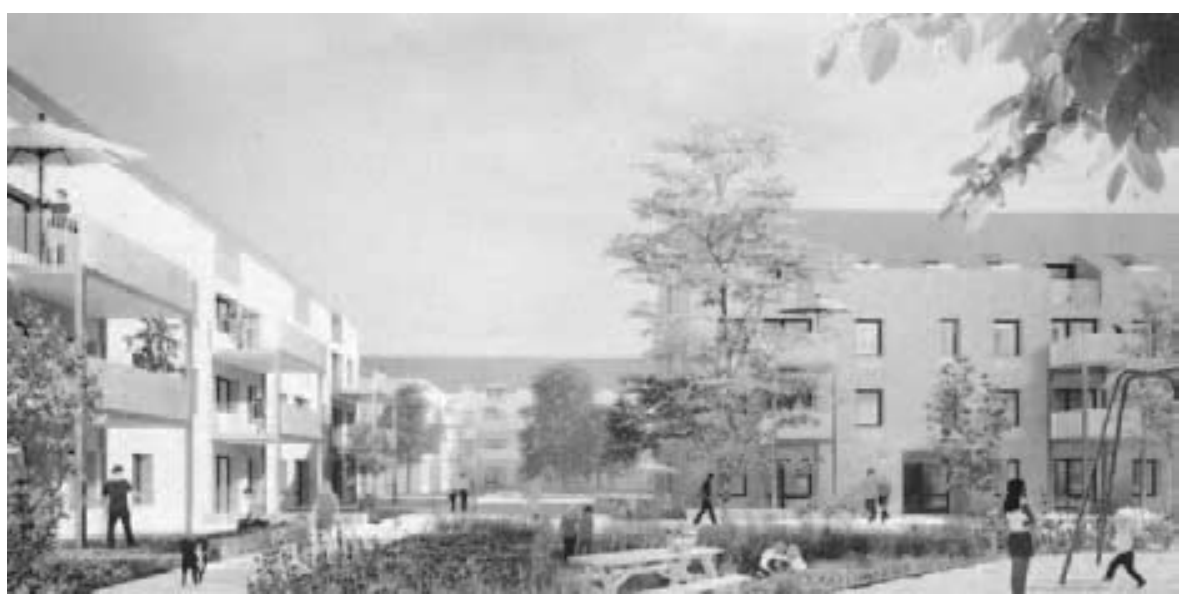

Figure 1.Abstract visualization of the project presented by 22Architekci architectural office in the competition for a multi-family residential and commercial housing complex in Wroctaw (copyright 22Architekci).

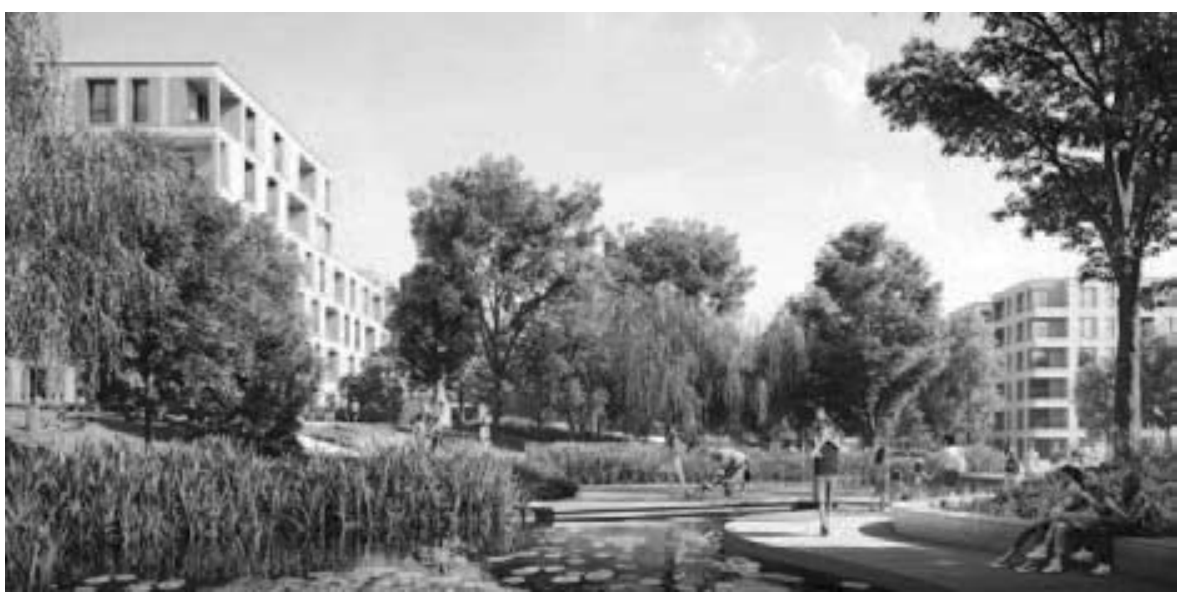

Figure 2. Photorealistic visualisation of the project presented by 22Architekci architectural office in the competition for a multi-family residential and commercial housing complex in Warsaw (copyright 22Architekci). 


\section{ARCHITECTURAL MODEL}

The physical model is a material, three-dimensional representation of the designed space, usually on a smaller-than-real scale, already used in Italy in the early Renaissance (Schilling, 2007). Depending on the design task and its scale, the model operates with different accuracy. The smaller the scale of the model, the more simplifications are usually employed, i.e. buildings become solids, streets are lines, greenery is represented with three-dimensional symbols, etc. Ideological models are used in the initial phase of the project: abstract solids and shapes that represent the main idea behind the creator's idea. These models are not usually reminiscent of their appearance or use of the materials in the final design and are a record of the main design idea, which is still in the author's consideration. For the presentation of the final design concept, architectural models directed to other recipients are used. Models are based on an appropriate scale and, depending on the purpose of creation, are made of specific materials. Thanks to a certain degree of abstraction forced by scale, the models allow retaining the overall picture of the design, omitting the details that are irrelevant at this stage. In Baumschlager Eberle's architectural practice view "model, if it's built right, represents a level of truth: the volumes are as great as they are. The distances are as far as they are. The conditions created as a result are those reproduced in the model" (Hollenstein, 2010, p.98).

In addition, physical models have one more important feature: thanks to them, the observer can view the space from almost every side, replacing two-dimensional drawings and plans. Therefore, there is no question of the

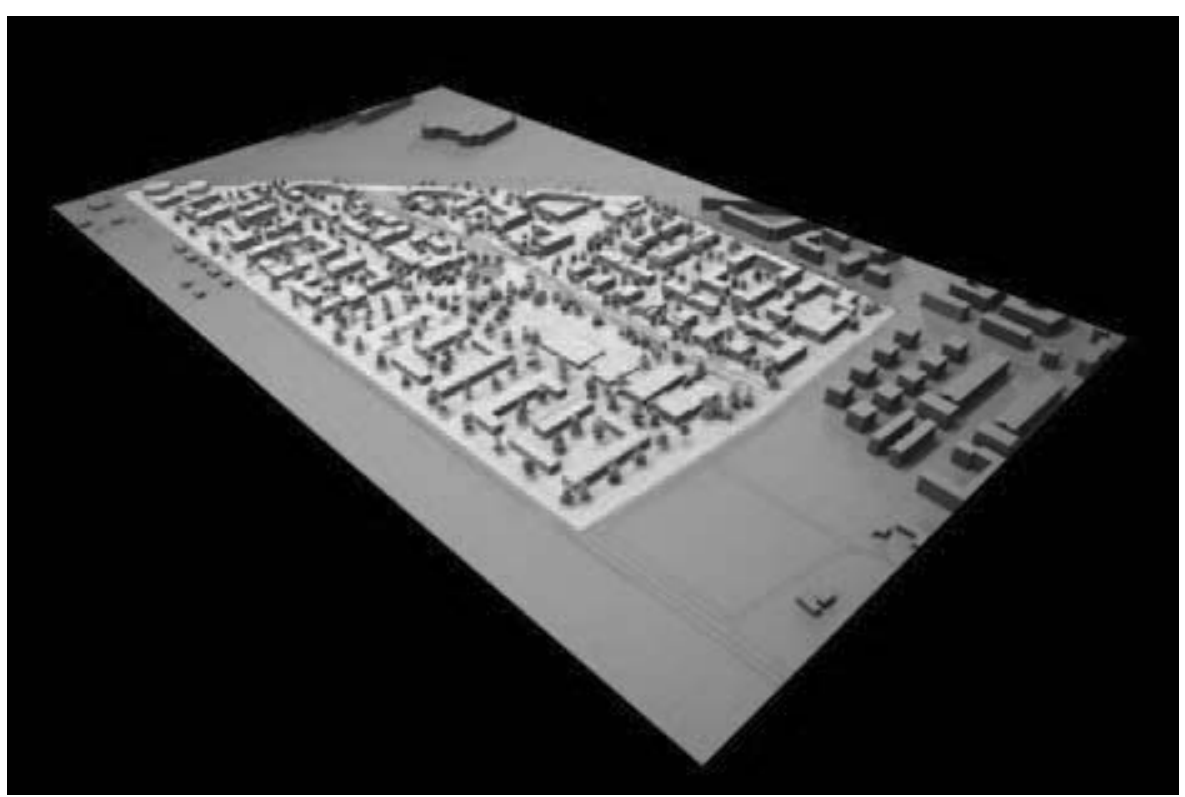

Figure 3. Urban model in the competition for a multi-family residential and service complex in Wroctaw (photo by the author). 
hypocrisy of reality, but only its simplification, allowing to see what is most important in the project. A model does not represent reality in a universal way. It uses the knowledge, memory and habits of the author's addressee of the message (Słyk, 2018).

It should be mentioned that the models can also be used at larger scales at later stages to create mock-ups, showing e.g. test elements in 1:1 scale at the construction site.

Below there are examples of the use of architectural visualisations and models in processes that result in the implementation of architectural design. The examples are divided according to the recipient of the presentation: professional and non-professional. The division results from various techniques, materials and scales used to create the model, and finally, from the purpose they are intended to serve.

\section{ARCHITECTURAL COMPETITIONS}

Architectural competitions are a widely recognized tool for project selection in the field of spatial planning or architecture, where the main evaluation criterion is the quality of design solutions. In this complex process, members of the jury evaluate the projects submitted for the competition, comparing project solutions proposed by the participants. To make an objective choice of the best project, the scope of the competition presentation, consisting of graphic design and model, must be identical for all entries. As a result, the jury receives a comparable overview of ideas, which can be related to the assessment criteria established in the competition regulations. Both visualisation and architectural model are usually mandatory elements of the competition submission, often including detailed guidelines for the preparation of these elements. Visualisations in competitions often cannot be photorealistic and must retain their monochrome colours so as not to affect the unprofessional judges who make up the jury. Similarly, architectural models usually have specific material and colour so as not to disturb the perception of the scale and make them comparable to each other. For example, in Swiss architectural competitions, only 1:500 scale models are practised. Presentations prepared in this way, together with architectural plans, diagrams and the descriptive part, constitute the overall competition work. Projects that create our landscape are selected on such bases, which only shows how important this element of the decision-making process is.

\section{SOCIAL PRESENTATIONS}

Public consultations are a tool used to study users' opinions regarding the designed space. They can have a supra-local character, e.g. when laying out local plans covering the space affecting the entire area of a city or town. In this situation, opinions are collected from residents and users regardless of where 
they live. On the other hand, there is a consultation of the local nature, when the designed space affects the surrounding residents. What is more, residents know the most about the functioning of their surroundings and are an irreplaceable source of information for designers. This knowledge is acquired in a variety of ways. The bases are interviews, surveys and observation of how space is used. On this foundation, architects create a design that can be presented on a model in the next stage. For this purpose, working, flexible models are used. This type of model is not used for the final presentation but allows one to work on the presented concept. Individual elements are mobile; they can be transformed, removed from the project or new ones can be added. During social consultations, the concept is presented on an urban model illustrating space on a larger scale, but in a simplified way. The model depicts streets, squares, green space and simplified buildings reduced to simple geometric blocks. The materials used and the style in which the models are prepared largely depend on the studio itself, but the basic premise is to present the design in a way that will be understandable to the recipient. For this purpose, for instance, materials that imitate the existing space are used and the colours correspond to the adopted symbolism of space, e.g. green represents recreation zones, parks, lawns, etc. A map or satellite image can be also used as a foundation. During the consultation stage, in which the model is used on location, researchers present a model that is later being developed. The model is designed to help interested participants imagine the proposed changes and collect their feedback. The model illustrates the proportions and sizes of the designed space and

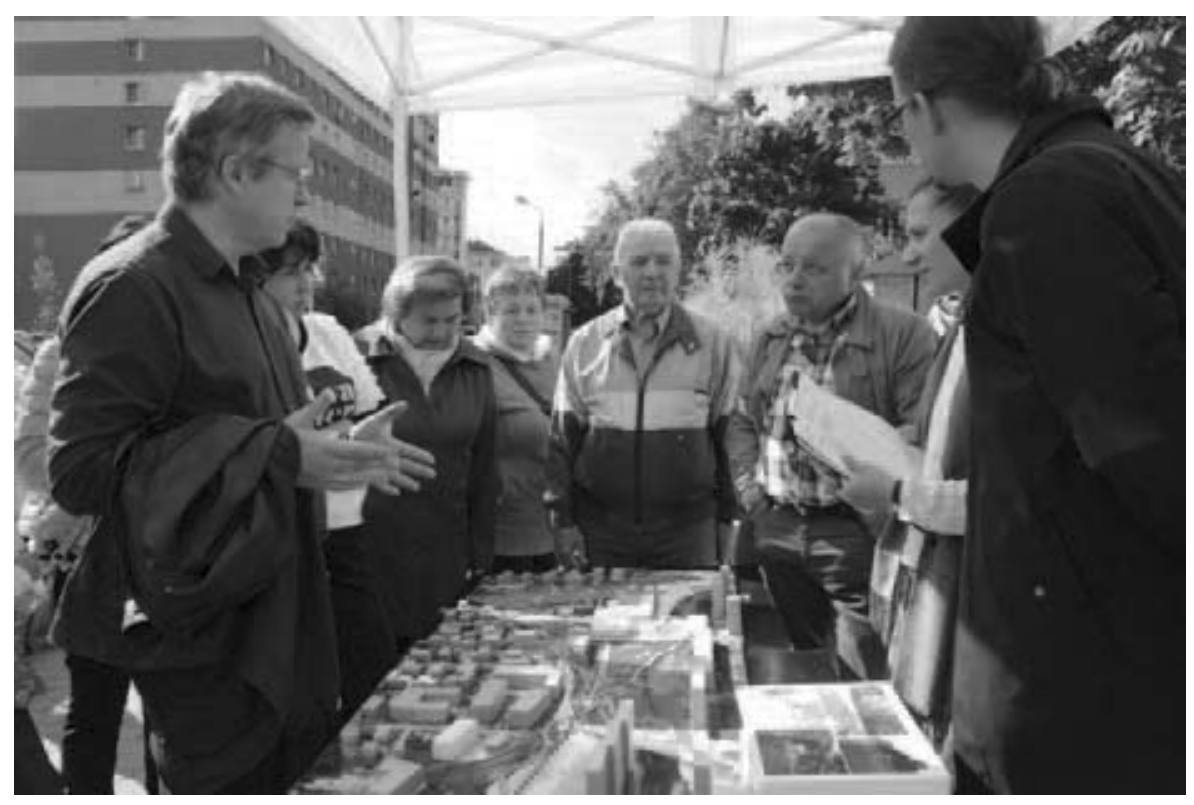

Figure 4. Presentation of the urban model of Niedźwiadek Local Center during the public participation process in Warsaw - Ursus (photo by the author). 
individual elements. Using the model, its recipient can compare the proposed changes with the existing space. Using the architectural model also prevents manipulation. The task of the model becomes a purely functional projection of the architectural concept in a tangible 3D object, which serves to deepen knowledge about the expectations of users for whom space is designed.

\section{CONCLUSIONS}

The right choice of presentation method for the addressee allows for a better understanding of the presented idea and, as a result, for more conscious choices made by the society, e.g. during public consultations, or by professional decision-making bodies in matters of public space or new buildings. A variety of methods of imaging the project vision available today have their individual features that favour or negatively affect the reception of works, by falsifying reality or its partial message. The solution that fully presents the designed object or space is a combination of different presentation techniques. The architectural model presents the size, scales and proportions of the space, building an information layer. In turn, visualisation is a narrative part, presenting the atmosphere of the designed place and referring to the emotions of the recipient. Thanks to this, the designer has a chance to present the proposed solutions in a holistic and comprehensive way and thus enables the recipient to objectively and consciously evaluate.

\section{REFERENCES}

[1] Centrum Konsultacji Społecznych Warszawa. (2016a). Raport z konsultacji społecznych dotyczacych stworzenia Centrum Lokalnego na placu Grunwaldzkim. [Report from the social consultation process for local center on Grunwaldzki Square]. Retrieved March 24, 2017, from http:/ / konsultacje.um.warszawa.pl/sites/konsultacje.um.warszawa.pl/files/cl_zoliborz_raport_z_ wiz_zs.compressed.pdf.

[2] Centrum Konsultacji Społecznych Warszawa. (2016b). Raport z konsultacji społecznych dotyczacych stworzenia Centrum Lokalnego Niedźwiadek. [Report from the social consultation process for local center Niedźwiadek]. Retrieved March 24, 2017, from http:/ / konsultacje.um.warszawa. $\mathrm{pl} /$ sites/konsultacje.um.warszawa.pl/files/cl_ursus_raport_ostateczna_wersja.compressed. pdf.

[3] Schilling, A. (2007). Basics. Modelbuilding. Basel: Birkhäuser.

[4] Hollenstein, R. (2010). Tools for Work and Communication in Baumschlager Eberle. Annäherungen / Approaches. Vienna: Springer-Verlag.

[5] Słyk, J. (2018). Modele architektoniczne. [Architectural models]. Warsaw: Oficyna Wydawnicza Politechniki Warszawskiej. 